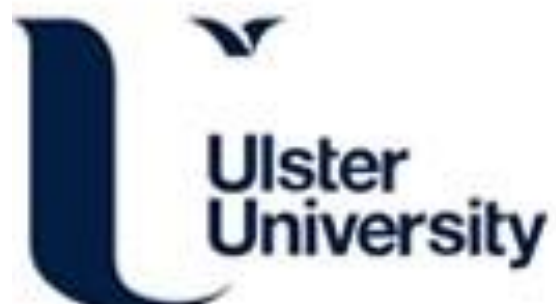

\section{Home Based Mobile Solution for Video Ambulatory EEG Monitoring}

Chacko, S., \& McCullagh, P. (2014). Home Based Mobile Solution for Video Ambulatory EEG Monitoring. In Unknown Host Publication (pp. 107-110). IEEE. https://doi.org/10.1109/IE.2014.23

Link to publication record in Ulster University Research Portal

\section{Published in:}

Unknown Host Publication

Publication Status:

Published (in print/issue): 30/06/2014

DOI:

10.1109/IE.2014.23

\section{Document Version}

Publisher's PDF, also known as Version of record

\section{General rights}

Copyright for the publications made accessible via Ulster University's Research Portal is retained by the author(s) and / or other copyright owners and it is a condition of accessing these publications that users recognise and abide by the legal requirements associated with these rights.

\section{Take down policy}

The Research Portal is Ulster University's institutional repository that provides access to Ulster's research outputs. Every effort has been made to ensure that content in the Research Portal does not infringe any person's rights, or applicable UK laws. If you discover content in the Research Portal that you believe breaches copyright or violates any law, please contact pure-support@ulster.ac.uk. 


\section{Home based mobile solution for video ambulatory EEG monitoring}

\author{
Shaji Chacko \\ Acute Physician \\ The Ulster Hospital, South Eastern Trust, Northern \\ Ireland, United Kingdom \\ drshajic@hotmail.com
}

\author{
Paul McCullagh \\ Reader Computing \& Mathematics \\ University of Ulster, Jordanstown, Shore Road, \\ Newtownabbey \\ pj.mccullagh@ulster.ac.uk
}

\begin{abstract}
A video electroencephalogram (EEG) is the gold standard test for the monitoring of long term epilepsy, differentiating types of epilepsy and investigations of nonepileptic seizures. The use of video EEG in current practice is significantly limited by cost and non-availability of resources, causing delays for patients. This development addresses whether the limitations can be overcome by mobile technology augmented by a web based ICT solution. The experiment demonstrated that disadvantages of hospital based video EEG can be addressed by using ambulatory EEG and IP cameras at the subject's home. The data obtained can potentially be of diagnostic significance, given sufficient technological rigor.
\end{abstract}

Anbulatory; electroencephalogram; video monitoring; remote diagosis

\section{INTRODUCTION}

The diagnosis of epilepsy can have significant physical, social, economic implications for a person [1]. Since various other conditions can mimic epilepsy like panic attacks, pseudo-seizures, it is recommended that the diagnosis of epilepsy should be made by a consultant neurologist [2]. The specialist would need all the evidence at hand to make this diagnosis. Currently the initial diagnosis is mainly based on a good history and reliable eyewitness account. Tests such as the electroencephalogram (EEG) [3] can confirm diagnosis and differentiate types of epilepsy, but a normal EEG cannot exclude epilepsy. The over interpretation of EEGs is common and is an important contributor to the misdiagnosis of epilepsy [4]. When clinical information and standard tests do not lead to a confident diagnosis, an in-patient Video EEG [5] is very useful, but the waiting times for these are very long and often the specialist would start the person on medication while waiting for these tests. Video EEG used for polysomnography would be ideal in investigating sleep disorders and excessive daytime sleepiness [6], but due to costs and non-availability of resources these are not routinely done. Due to the incidence of delay in diagnosis this paper investigates the use of low cost technology to overcome limitations.

Studies have shown that EEG recordings when combined with video capture of the event can aid in diagnosis of epilepsy [7]. Ambulatory EEG recordings have increased yield of pickup of interictal epileptiform discharges (IED) due to longer recording times [8]. Video EEG may even aid the large number of elderly population who are misdiagnosed with the condition when they present with syncope [9]. Studies have also proven that short term video recordings may be used as a screening tool for longer in-patient video EEG recording [10]. Literature analysis revealed preliminary work has already taken place to have a telemonitoring video EEG service [11]. Tele-EEG is a feasible, secure, timely and effective method of providing an EEG service [12].

Ambulatory EEG (AEEG) monitoring technology has evolved such that portable recordings of up to 36 channels, over several days are possible. AEEG recording increases the yield of IED detection compared to a routine EEG [13]. It is also less expensive than an inpatient video EEG recording but it lacks clinical correlation that can be obtained by direct observation of the patient during the episodes. It requires prolonged EEG technician time to analyze these recordings. Since AEEG requires recording for a few days, long term recording would need low power devices for such recording [14]. AEEG has a large number of artefacts due to the nature of the recording environment [15]. Devices in the market have recently focused on improving the following technological limitations:

- Noise reduction for reducing artefacts

- Portability-Size and Weight

- Battery life (Power consumption up to 96 hours)

- Sampling rates (higher to increase resolution)

- Complimentary modes, e.g. ECG and pulse oximetry for sleep studies

- Sufficient memory for longer term recording

Video EEG monitoring is a more specialized form of an EEG test in which the patient is constantly monitored over a video screen. This allows doctors to observe brainwave electrical activity during the time a seizure is occurring. This test currently requires an admission to the hospital with an average stay is 3 to 5 days. It is more expensive than a routine EEG. The yield of a Video EEG increases with prolonged recording time, but this has an impact on time for analysis. Patient reviews (www.patientslikeme.com) for video EEG indicated that the main user limitation of this test was its need for hospitalization.

This study explores 'proof of concept' to determine if technological advances such as Internet Protocol (IP) cameras combined with ambulatory EEG can support diagnostic accuracy, help reduce waiting times and reduce cost. This could help screen the large number of patients who are waiting for an in-patient test. Remote viewing and analyzing data would help reduce costs, minimize misdiagnosis, and reduce the number of people being started on anti-epileptic medication whist awaiting formal tests. 


\section{METHODOLOGY}

A literature search into AEEG and its clinical relevance concluded that technology has evolved to make it as effective as an in-patient EEG. The level of sophistication needed to differentiate non epileptic attacks from epileptic attacks could be low and yet yield clinically relevant data to achieve valid diagnosis especially if this could be co related with video recording and electro cardiogram (ECG) trace of the subject.

Our proof of concept prototype comprises ambulatory EEG device, IP camera to capture data that can be viewed and interpreted remotely. An application was made to the regional ethics committee. The project only posed minimal risk from accidental risks since none of the tests would be invasive. The main concern would be to protect the privacy of the participant since video recordings would be made of the participant. Other risks would involve those of using a sterile lead placement on scalp to minimize the risk of infection. This was achieved by using disposable leads as done in routine practice for every EEG recording.

The components of the Ambulatory Video EEG include:

a) Ambulatory EEG: The device chosen for the practical part of the project was the Micromed (Model Morpheus $\left.{ }^{\circledR}\right)$. It is a small hand held device that can record up to 4 channels and used in applications like Standard Polysomnography and EEG, Ambulatory Polysomnography and EEG, Long Term Monitoring of Epilepsy.

b) Video Capture Device: A wide variety of video capture devices were found in the market. The device needed to meet the following requirements: wireless capability, flexible use: can be easily moved around, capable of 2 way communication over the single connection, Internet ready, good night vision capability (Infra Red Illuminator), good quality resolution on video capture (At least 640X840 and more), Pan/Tilt/Zoom would be beneficial features but not mandatory, Live View Mode should be possible on a smart device as a phone, local memory card storage, secure transmission: data encryption and authentication method for data transfer such as WPA2.

A D-LINK IP Camera-942 L, was used. It had Wireless-N capability, and recorded video in a MJPEG format. For data streaming IP devices, need at least $3 \mathrm{Mbps}$ to achieve a 10 frame/sec data transfer, which meant the need broadband at the subject's house. The broadband connection needed to be connected to a wireless router since it would limit the functionality of a wireless IP camera if were limited to a wired connection. This would also limit the number of cameras that could be installed.

Video Management Software: The camera chosen was Internet ready. Initial setup, maintenance was done over the Internet. An free application was available (mydlink ${ }^{\mathrm{TM}}$ ) on the android marketplace to view video remotely on demand (www.mydlink.com).

Setting up the Video Recording: The video capture device needed to be configured to work at the network of the subject's home. This would need to be setup by a person with technical expertise and takes about ten minutes.

The camera should be setup in an area where the subject spends most of his time, and depending on the nature of study may need to be in the bedroom where the patient sleeps. The setup of more than one camera to monitor different areas would be recommended as the subject could move to different rooms. The software was configured to record to a local computer but it had the capability to record to a Network Video Recorder. Video was also recorded on to a Micro SD card on the device.

It was required to synchronize time on both the EEG and video capture devices. The EEG leads were attached to the head and 2 leads to monitor ECG to the chest wall. The whole process took about 15 minutes. The technology was comfortable to wear and was not obstructive in anyway. Once at the home environment, recording can be commenced remotely and instructions can be relayed to the patient due to the two-way audio transmission capability. During the recording the investigator simulated changing EEG data by doing various timed activities like eating, opening and closing eyes, sleeping, simulating a pseudo seizure. All activities were recorded in a dairy.

The EEG data were stored locally, later uploaded onto the hospital computer to be compared to the video. The electro physiologist at the hospital viewed EEG and video data sources. Using remote desktop software the recordings can be viewed in parallel using remote desktop onto smart devices.

\section{AMBULATORY VIDEO EEG}

Recording was achieved with the help of a regional Neurophysiology Clinic (Mater Hospital, Belfast). The principal investigator volunteered as subject to address feasibility of recording at his home environment. This involved the investigator installing IP cameras. A series of EEG with simultaneous video recordings were then undertaken (Figure 1).

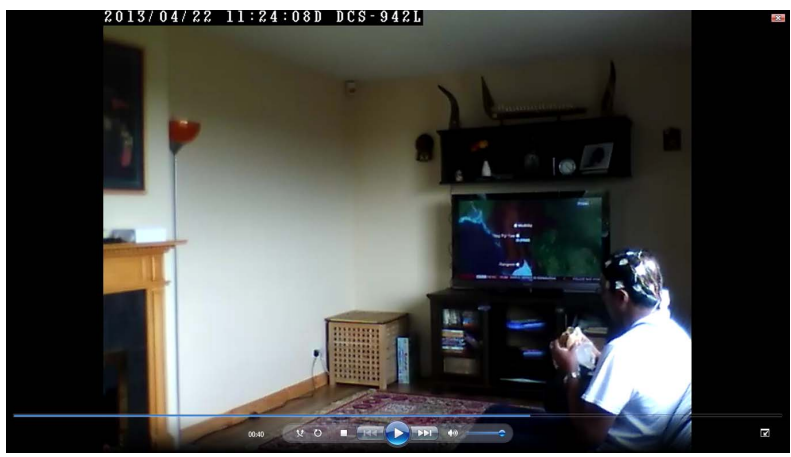

Figure 1. Ambulatory Video EEG (remote monitoring)

The data were viewed remotely at the time of recording. Aspects of data quality, user experience, and technical issues of remote transmission were investigated. Technical challenges include those of data transmissions and data compression to enable accurate and reliable transmission.

\section{RESULTS}

The authors wish to emphasize that the project only involved the principal investigator testing its concept to look at the feasibility of creating such a system and that no actual measurements were made yet as to its fitness of medical use. 
On viewing the EEG trace from the Micromed Morpheus ${ }^{\circledR}$ device on the Micromed software (Figure 2) and running the video obtained from the DLink camera EEG activity could be correlated with video activity. A difference in time stamp was noted on analyzing the results on both recordings that led to some asynchrony in recordings. A clinician who felt the data would potentially have diagnostic accuracy also viewed the results. The lead for Electro Physiology Department within in the hospital expressed that 'The recordings were of good quality and if we could get it synchronized then it could be diagnostically accurate'. She was satisfied with the quality of the video and 'felt it was as good as her in-patient recording'.

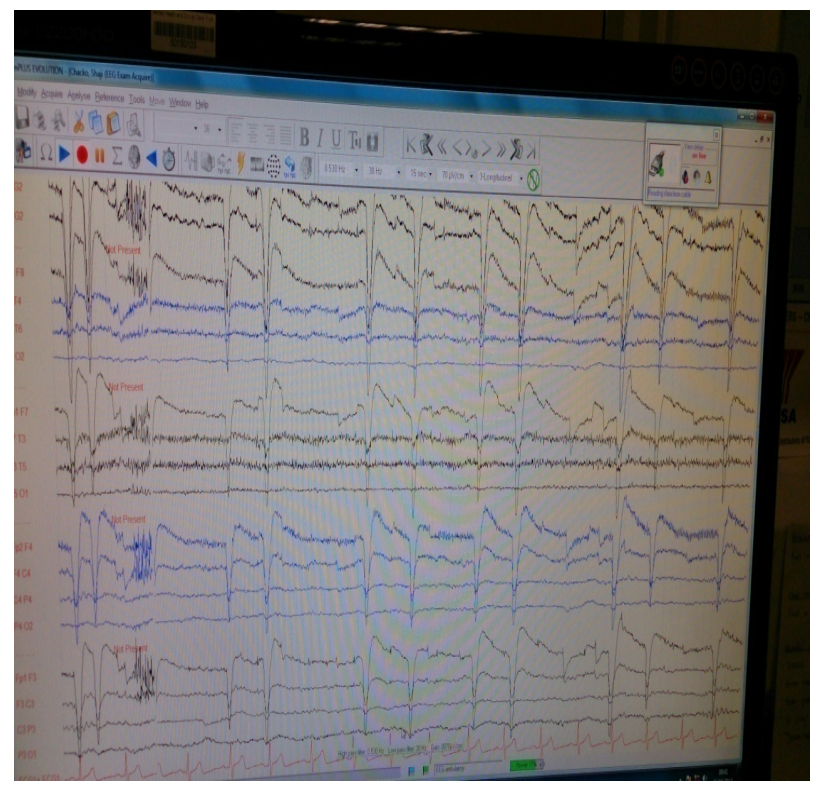

Figure 2. Viewing the participant's home recorded EEG on the Micromed software

The issues encountered during the recording were the following:

Camera setup: It would need a person with technical knowledge to setup the camera to link to the network through patient's home broadband connection. One would also need to test broadband speeds to ensure adequate bandwidth for reliable transmission.

Viewing angle: It could take some time to get optimal views of the study area, i.e. to decide what part of the room to focus on. If this has to be setup remotely, then cameras would need the Pan, Tilt and Zoom facility, or this it could be done by a trained personnel during setup. Since the cameras are small and have the possibility to move, it would be recommended to have the 2 way audio so that the person monitoring remotely could ask the patient to turn the camera to a good viewing angle.

Data Storage: A one hour recording at $640 \times 480$ resolution of video requires around $1.2 \mathrm{~GB}$ of disk space, so a minimum disk space of 500GB is required, if we were installing 2 or more cameras for a 3-4 day recording.

Data Transfer: The web based software captured data on a local personal computer in a MJPEG format in $15 \mathrm{MB}$ snips. It wrote files in different folders labelled by date and time, it was convenient to locate a particular point of recording, but this had to be transferred on to a USB for transfer. It would have been nice to have this on a single Network Video Recorder.

Time synchronization: It was on analysis of the video data, EEG data and event diary that we found that the events did not correlate accurately. This was due to a 57 sec difference in time stamps of both recording. This was easily rectified manually, but would have been preferable to synchronize devices to a common server time.

The proposed practice takes away the current limitations and adds value for current tests performed without video capture like stand alone ambulatory EEG, or standard and ambulatory polysomnography. It would make long term monitoring for epilepsy possible at very low costs. It would change current practice to bring benefits to patients.

Transmission of high definition images 1080p (1920X1080p) would require a image transfer of 30 frames per second.

Advantages of proposed practice:

- Low cost (Fraction of current costs)

- Devices readily available in the marketplace

- Easy to integrate with current practice

- Decrease waiting times for patients for current test

- Remote monitoring

- Scalable

Disadvantages of proposed practice:

- Test can be inconclusive

- Need broadband, minimum wireless infrastructure in the patients house which can be a constrain sometimes

- Data security issues. The proposed system of using IP cameras should use data encryption and authentication methods.

Current practice has been restricted to ambulatory EEG by comparison with video EEG, in most cases due to the later being very expensive and to the current waiting times. Studies have revealed a cost reduction of $55-80 \%$ per patient with the use of outpatient video EEG compared to Inpatient video EEG [16]. The proposed solution to augment the diagnostic yield and accuracy of the investigation would have to be proved with proper research.

The proposed solution can be further upgraded to offer better video capture by using High Definition video capture. There are plenty of devices in the market that meet the criteria. Smart analytics on the device could trigger alerts, which could be sent via a mobile platform for instantly alerting the clinician who could log in to view live video. Possible areas of application include: intractable epilepsy, long term EEG monitoring for patients like those who need worked up for surgery [17], investigations of syncope where a neurological cause is suspected, pseudo seizures, and all sleep studies.

\section{ACKNOWLEDGMENT}

The authors would like to acknowledge the cooperation of the Neurophysiology Department of the Mater Hospital, Belfast. 


\section{REFERENCES}

[1] Jennum P, Gyllenborg J and Kjellberg J 2011: The social and economic consequences of epilepsy: a controlled national study. Epilepsia ;52(5):949-56.

[2] Scottish Intercollegiate Guidelines Network (SIGN) 2003 Diagnosis and Management of Epilepsy in Adults A national clinical guideline.Chowdhury FA, Nashef L, Elwes RD; Misdiagnosis in epilepsy: a review and recognition of diagnostic uncertainty. Eur J Neurol. 2008 Oct;15(10):1034-42.

[3] Kennett R. 2012: Modern electroencephalography. J Neurol. Apr;259(4):783-9.

[4] Benbadis SR, Lin K Epub 2008 Feb 8. Errors in EEG interpretation and misdiagnosis of epilepsy. Which EEG patterns are overread? Eur Neurol. 2008;59(5):267-71.

[5] Uysal-Soyer O, Yalnizoğlu D, Turanli G 2012 The classification and differential diagnosis of absence seizures with short-term video-EEG monitoring during childhood. Turk J Pediatr. JanFeb;54(1):7-14

[6] Engstrøm M, Rugland E, Heier MSPolysomnography (PSG) for studying sleep disorders. TidsskrNorLaegeforen. 2013 Jan 8;133(1):58-62.

[7] Watemberg N, Tziperman B, Dabby R, Hasan M, Zehavi L, Lerman-Sagie T; Adding video recording increases the diagnostic yield of routine electroencephalograms in children with frequent paroxysmal events ; Epilepsia. 2005 May;46(5):716-9.

[8] Gil-Nagel A, Abou-Khalil B. Electroencephalography and videoelectroencephalography.HandbClin Neurol. 2012;107:323-45.

[9] LaRoche S, Taylor D, Walter. Tilt table testing with video EEG monitoring in the evaluation of patients with unexplained loss of consciousness. PClin EEG Neurosci. 2011 Jul;42(3):202-5.
[10] Tallawy HN, Fukuyama H, Kader AA, Kamel NF, Badry R. Role of short-term outpatient video electroencephalography in diagnosis of paroxysmal disorders.Epilepsy Res. 2010 Feb;88(2-3):179-82. Epub 2009 Dec 3.

[11] Campos C, Caudevilla E, Alesanco A, Lasierra N, Martinez O, Fernández J, GarcíaJ.Setting up a telemedicine service for remote real-time video-EEG consultation in La Rioja (Spain).Int $\mathrm{J}$ Med Inform. 2012 Jun;81(6):404-14. Epub 2012 Feb 10.

[12] Coates S, Clarke A, Davison G, Patterson V.Tele-EEG in the UK a report of over 1,000 patients. JTelemedTelecare. 2012;18(5):2436. Epub 2012 Jul 11.

[13] Dash D, Hernandez-Ronquillo L, Moien-Afshari F, Tellez-Zenteno JF. Ambulatory EEG: a cost-effective alternative to inpatien video-EEG in adult patients. EpilepticDisord. 2012 Sep;14(3):2907

[14] Patel K, Chern-Pin Chua, Fau S, Bleakley, C.J. Low power realtime seizure detection for ambulatory EEG . Pervasive Computing Technologies for Healthcare, 2009. PervasiveHealth 2009

[15] Casson A, Yates D, Smith S, Duncan J, Rodriguez-Villegas E 2010 Wearable electroencephalography. What is it, why is it needed, and what does it entail? IEEE Eng Med Biol Mag. May-Jun;29(3):4456

[16] Foley CM, Legido A, Miles DK, Grover WD; Pediatr Neurol. Diagnostic value of pediatric outpatient video-EEG; 1995 Feb;12(2):120-4

[17] Guerreiro CA, Montenegro MA, Kobayashi E, Noronha AL, Guerreiro MM, Cendes F; Daytime outpatient versus inpatient video-EEG monitoring for presurgical evaluation in temporal lobe epilepsy. J ClinNeurophysiol. 2002 Jun;19(3):204-8.

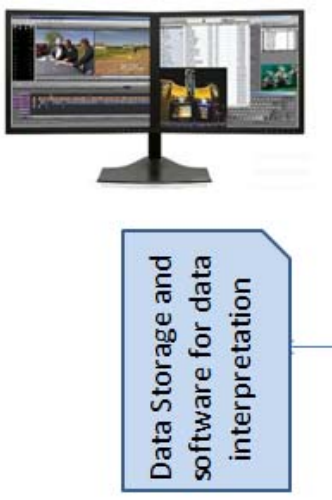

Clinical Environment

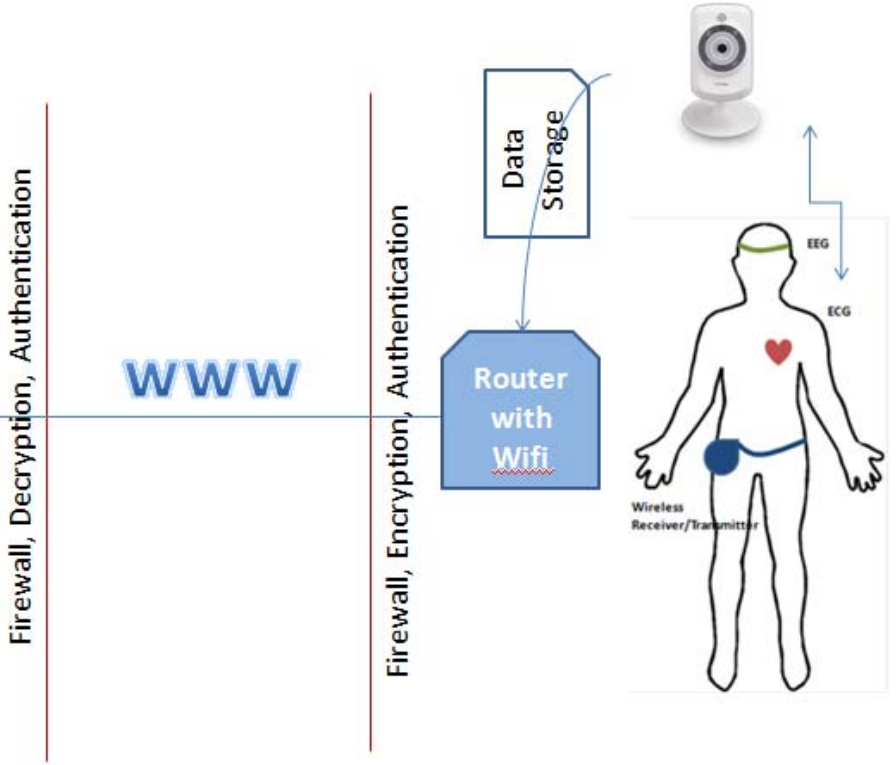

Patients Environment

Figure 3. Data transmission for video EEG 